Corbett, J.M. (2008) 'Towards neuroscientific management?: geometric chronophotography and the thin-slicing of the labouring body'. Management and Organizational History, 3, 107-125.

Towards a Neuro-Scientific Management? Geometric Chronophotography and the Thin-Slicing of the Labouring Body

\author{
J. Martin Corbett \\ Warwick Business School \\ University of Warwick \\ COVENTRY CV54 7AL \\ United Kingdom
}

Martin.Corbett@wbs.ac.uk 


\title{
Towards a Neuro-Scientific Management? Geometric Chronophotography and the Thin-Slicing of the Labouring Body
}

\begin{abstract}
The conventional history of the labour process suggests that Taylorism played a key role in the development and popularisation of production management techniques in general, and work science in particular. This paper argues that the work of Herman van Helmholtz, Edwaeard Muybridge, and Jules Etiennes Marey helped establish an ideology of the labouring body which not only pre-dated the work of Frederick Taylor, but which continues to influence management thinking and practices today.
\end{abstract}

Key words $\bullet$ Chronophotography $\bullet$ Helmholtz $\bullet$ Marey $\bullet$ Psychophysics $\bullet$ Subliminal - Unconscious 


\section{Towards a Neuro-Scientific Management? Geometric Chronophotography and the Thin-Slicing of the Labouring Body}

\section{The First Law of Thermodynamics and the Search for Lost Time}

In his best-selling book, Blink, Malcolm Gladwell (2006) invites us to consider the power of the unconscious in our decision-making. He argues that we often make crucial unconscious inferences in the first two seconds of our interactions with people and objects. From Ambady and Rosenthal (1993), he borrowed the term 'thin-slicing' to designate this activity. The article you are now reading is also about 'thin-slicing', but the story unfolds within a considerably thicker slice of time, and the slice in question, at half a second, is significantly thinner than Ambady and Rosenthal's original slice of half a minute or the two second 'blink'. Gladwell's book concerns itself with how the efficiency of human decision-making might be improved by an awareness of the power of the brief interjection of the unconscious in our day-to-day thinking. This paper concerns itself with the role of embodied unconsciousness in organisational behaviour, with an emphasis on the efforts of scientists and managers to improve the efficiency of the ways in which goods are produced and consumed in the modern world through the exploitation of that thin slice of time residing between sensation and consciousness. This paper explores how some of the socio-economic, ideological and technological developments which began in the nineteenth century have ushered in 'a micro-biopolitics, a new domain carved out of the half-second delay which has become visible and so available to be worked upon through a new series of entities and institutions' (Thrift, 2004: 66).

Gottfried Wilhelm Leibniz was probably the first modern philosopher to identify the 'blink'. In the posthumous publication in 1765 of his New Essays on Human Understanding, he described the mind as a marriage of conscious and unconscious parts, and suggested that behaviour could be influenced by what he called minute perception that is, perception occurring outside of conscious awareness. However, this idea was not taken seriously by philosophers or scientists for nearly 100 years, at which time the scientific quest to understand the phenomenon began in earnest. This quest to thin-slice 
time was propelled into Western cultural consciousness following a meeting in Paris between a German, a Frenchman and an Englishman - Hermann von Helmholtz, Etiennes Jules Marey, and Eadward Muybridge - on the evening of September $26^{\text {th }} 1881$. Despite meeting 125 years before the publication of Blink, these three men would have agreed wholeheartedly with Gladwell's contention that '[e]very moment - every blink - is composed of a series of discrete moving parts, and every one of those parts offers an opportunity for intervention, for reform and for correction' (2006: 241). The meeting in Paris was arranged to debate precisely this issue.

But our story begins in 1847 in the laboratory of the celebrated German physicist and physiologist, Hermann von Helmholtz. It was here that Helmholtz elaborated the universal law of the conservation of energy - the law we now refer to as the first law of thermodynamics - which argued that the forces of nature are forms of a single, universal energy that can neither be created nor destroyed. In his public lectures and writings Helmholtz made it clear that all manifestations of nature obeyed this law. Echoing the mechanistic philosopher La Mettrie, he regarded the human body as itself an engine or motor.

The idea of work for machines, or natural processes, is taken from comparison with the working power of man; and we can therefore best illustrate from human labour the most important features of the question with which we are concerned... Now, the external work of man is of the most varied kind as regards the force or ease, the form and rapidity, of the motions used on it, and the kind of work produced. But both the arm of the blacksmith who delivers his powerful blows with the heavy hammer, and that of the violinist who produces the most delicate variations in sound, and the hand of the lace-maker who works with threads so fine that they are on the verge of the invisible, all these acquire the force which moves them in the same manner and by the same organs, namely, the muscles of the arms. An arm the muscles of which are lamed is incapable of doing any work; the moving force of the muscle must be at work in it, and these must obey the nerves, which bring to them orders from the brain. That member is then capable of the greatest variety of motions; it can compel the most varied instruments to execute the most diverse tasks...Just so it is with machines (Helmholtz, 1873: 64). 
Three aspects of human labour power troubled Helmholtz. One was the fact that muscles suffer from fatigue. The second was the time lag between an 'order' being received by the nerves and the execution of that order by the muscles. This phenomenon, which modern day physiologists explain in terms of 'axonal conduction velocity', Helmholtz (1850/1948) called, more simply, an element of 'lost time'. The third contributory factor to the inefficiency of the body (the second element of lost time) Helmholtz discovered when studying reaction time - the time it takes a subject to respond to a consciously perceived stimulus - which he found to be far slower than even the combined conduction times he had recorded for sensory and motor activities. Helmholtz argued that a great deal of brain processing must occur unconsciously before any conscious perception of an object. He therefore concluded that much of what goes on in the brain is not represented in consciousness, but that the perception of objects depends upon 'unconscious inferences' made by the perceiver. If the body's lost time could be brought to conscious awareness, measured, and analysed, Helmholtz believed that efficiency could be enhanced by the appropriate intervention, reform and correction.

It was these perceived inefficiencies of the human motor that heralded the search for a more efficient conservation and use of energy - a search which, as Rabinbach (1990) argues, was to exert a profound influence on Western political and socio-economic ideologies in the second half of the nineteenth century and beyond. Rabinbach deploys the rather inelegant neologism of 'social Helmholzianism' to describe this 'program of social modernity that conceived of the working body as a system of economies of force and as the focal point for the new techniques that could eliminate social conflict whilst ensuring productivity' (ibid. 120-1).

Unsurprisingly, the military were not slow to catch on to the potential benefits of such an ideology. For example, in the aftermath of France's defeat in the 1870-1 FrancoPrussian war, the work of the French physiologist Etiennes Jules Marey was sponsored by the French Ministry of War. The Minister of War held the view that the loss of the war was due, at least in part, to the inefficient use of the energy contained in the bodies of French soldiers and horses. Energy was latent within all members of society and the Ministry was instructed to rebuild its physically and mentally demoralized population. They believed that physiologists such as Marey should be at the centre of government- 
supported activity to help science bring the forces of nature and society under the control of the State. It is perhaps ironic that Marey's work should have been inspired by the pioneering work of Helmholtz, who was a recipient of the Iron Cross in 1871 for his contribution to the Prussian war effort.

Before the war, Marey had been studying and researching muscular forces, as well as working on physical education and gymnastics. He regarded Helmholtz's work on thermodynamics as 'the most remarkable theory of modern times' and set himself the goal of describing the economy of motion and to establish the laws of motion of the body. For Marey, Helmholtz's 'lost time' was the basic component of this economy and he hoped that the graphical method favoured by both men would enable the direct measurement of physiological time. 'All movement is the product of two factors: time and space; to know the movement of a body is to know the series of positions which it occupies in space during a series of successive instants' (Marey, 1878a: xi). The Frenchman distrusted any science based on unaided visual perception and was particularly hostile to a physiology based on vivisection. His graphical method enabled lost time to be recorded and corrected through 'the study in situ of living instruments'. According to Marey, the human sensorium was incapable of registering the fine movements of organic systems and so he argued that his mechanically produced graphic maps of the body possessed an objectivity that unaided human perceptions did, indeed could, not.

His early work involved the use of various graphical inscription devices to capture bodily movement directly. For example, he developed the sphymograph which measured the displacement of an artery wall at the pulse point of a wrist of a human body. A lever was attached at one end of the pulse point and the other end at a stylus. The stylus was brought into contact with a strip of smoke-blackened paper moved by a clockwork mechanism. The resulting graph measured the ebb and flow of arterial blood. Thus, the sphymograph, by measuring features of the pulse, translated the functions of the heart into a graphic language. In 1871, Marey extended this graphical method to animal locomotion and developed pneumatic techniques for transmitting information about changes in the position and speed of a horse's hooves. This information was recorded on a blackened cylinder strapped to the horse rider's back, and the results were graphically 
displayed as a kind of musical notation indicating both time and space (see figure one). He published his findings in the book La Machine Animale the following year.

Meanwhile, in California, far from the horrors of the Franco-Prussian war, the president of the US Central Pacific Railroad - Leland Stanford - was also developing an interest in horses. On the advice of his doctor, Stanford, a former governor of the state of California, withdrew from active involvement in his railway business to pursue the systematic acquisition, breeding, training, and racing of horses. In June 1870, he purchased a six year old gelding called Occident and set himself the challenge of making it the fastest race horse in the US. Along with Mark Hopkins, treasurer of Central Pacific Railroad, he began intensive research into equine anatomy and animal locomotion. The two men applied their findings rigorously and, within two years, Occident had earned a national reputation for its endurance and speed on the race-track.

\section{FIGURE ONE ABOUT HERE}

Not one to rest on his laurels, Stanford was determined to increase the efficiency of his entire stable of racehorses. Crucial to such an endeavour was solving the problem of whether a speeding horse propelled itself by its hind quarters or by pulling itself by its fore quarters. Initially, he attempted to measure the depth of the impression left by a horses' hooves on a smoothed sandy track, but results were difficult to decipher. But then, in April 1872, his studies were given fresh impetus by his well-publicised involvement in a controversy which had been captivating horse racing enthusiasts in the US for some time: was there a moment when all four feet of a racehorse were off the ground? Marey's graphical notations of horse locomotion, published just months earlier, certainly suggested to Stanford that this was the case ' (Muybridge, 1879: 246). However, the results were inconclusive when applied to a horse moving at race track speed, and Stanford resolved to use photography to provide the data necessary to settle the controversy.

So it was in 1872 that the celebrated landscape photographer Eadward Muybridge was commissioned to take the necessary photographs of Occident at Stanford's ranch in Sacramento. At first, Muybridge had tried to expose photograph film manually by 
snatching the cap off the camera lens as the horse streaked past. After two days of trying, the best photograph he could obtain was little more than a blurred shadow. On the third day, he rigged up a crude shutter made of two slats, tripped by a string running across a track at chest height. When the horse broke the string, the two slats slid in opposite directions across the front of the camera--and for five-hundredths of a second, a gap opened that was sufficient to expose the film. This ingenious apparatus provided, in the words of the Alta California newspaper, 'a great triumph as a curiosity in photography - a horse's picture taken while going 38 feet in a second!' The photograph showed Occident with all four hooves off the ground. As far as Muybridge was concerned 'the object of the experiment was accomplished' (Muybridge, 1881: 13). However, not everyone was convinced by the silhouette drawings derived from his series of twelve grainy photographs and it wasn't until 1877 that Muybridge finally took a definitive series of twelve 'instantaneous photographs' of Occident (which were duly rewarded with a medal from the jurors of the Twelfth Industrial Exhibition in San Francisco that November). The influence of these photographs (shown in figure two) was destined to spread far wider than the West Coast horse racing fraternity.

Back in France, Marey saw Muybridge' series of photographs of Occident in the journal La Nature, and immediately wrote to the editor:

I am lost in admiration over the instantaneous photographs of Mr Muybridge, which you published in your last number of La Nature. Can you put me in correspondence with the author? I want to beg his aid and support to solve certain physiological problems so difficult to solve by other methods; for instance, the questions connected with the flight of birds. I was dreaming of a kind of photographic gun, seizing and portraying the bird in an attitude, or better still, a series of attitudes, displaying the successive different motions of the wing. Cailletet informed me that he had formerly essayed something similar, with encouraging results. It is evident this would be an easy matter for Mr Muybridge to accomplish, and what beautiful zoetropes he could give us, and we could perfectly see the true movements of all imaginable animals. It would be animated zoology (Marey, 1878b: 29). 


\section{FIGURE TWO ABOUT HERE}

Indeed, within six months the editors of both The Field (UK) and Scientific American (US) magazines announced they had successful mounted Muybridge's pictures in a zoetrope. But it was Muybridge, in September 1879, who was to develop the most sophisticated way of projecting his photographic images onto a screen.

To this instrument I gave the name of Zoopraxiscope; it is the first apparatus ever used, or constructed, for synthetically demonstrating movements analytically photographed from life, and in its resulting effects is the prototype of all the various instruments which under a variety of names, are used for a similar purpose at the present day (Muybridge, 1881: 14).

As Robert Haas (1976: 120) observes, whilst not a completely new invention, the zoopraxiscope remained the only commercially demonstrated motion picture machine for more than a decade, or at least until Thomas Edison mass -produced his Kinetoscope, which was more viewer than a projector. The original projector survives and can be seen in the Library Museum in Muybridge's home town of Kingston-upon-Thames in the UK.

When Marey heard of Muybridge's invention, he could scarcely contain his excitement. Discovering that the Englishman was to embark on a European tour demonstrating his photographs, Marey persuaded him to come to Paris so that he could see the miracle of 'animated zoology' for himself. So it was that on the evening of September $26^{\text {th }} 1881$, Marey threw a dinner party at which Muybridge, along with his zoopraxiscope, was the guest of honour. Hermann von Helmholtz also attended. Marey and Helmholtz were both committed to the use of graphical devices to measure motion, and both shared a frustration with the limitations and inaccuracies of their own chronographic devices. The readout from Helmholtz's kymograph, for example, captured the minute movement of a frog's leg muscles but these could only be read via a microscope and he was obliged to make enlarged free-hand drawings of them. He much preferred the visual clarity of the images produced by the phenakistoscopes and rotating stroboscopic discs used in his studies of visual persistence (i.e. the tendency for the effect of a stimulus to remain visible after its extinction), but the results of these studies relied on 'unscientific' and subjective self-reports. Like Marey, Helmholtz was keen to take the 
human experimenter/observer out of the experimental loop, and instantaneous photography seemed to offer an elegant technological solution.

The dinner party was remarkable enough to warrant three paragraphs in the French newspaper, La Globe. From the report we know that the guests were extremely impressed by the zoopraxiscopic presentation - the apparently moving pictures suggesting a 'défilé diabolique.' Marey, in particular, was delighted that the show concluded with the showing of a series of instantaneous photographs of birds in flight. By all accounts Helmholtz found the demonstrations riveting, but Marey has later to confess some disappointment. The illusion of motion produced by the zoopraxiscope seemed to simply reproduce what the unaided eye could already see (courtesy of the phenomenon of visual persistence), whilst the individual photographs enabled temporal processes to be fixed and analysed to reveal phenomena invisible to the naked eye. This led Marey to a keen interest in the movement between the photographs rather than the illusory motion created by their projection from Muybridge's new machine. The uncaptured instances between the photographs may reveal the secret of Helmholtz's 'lost time', and it was this that Marey wanted to visualise, measure and analyse. He halted his graphical method studies of motion and turned, with Muybridge's guidance, to his own brand of instantaneous photography.

\section{Geometric Chronophotography and the Regimentation of the Body}

Muybridge's photographs were taken by a series of twelve cameras which were successively triggered by wires strung across the path of the moving horse or, more problematically, across the flight path of a bird. But Marey, who had a lifelong interest in aeronautics and the study of flight, felt that the tripping of wires was far too imprecise a measure of time and set about designing a more accurate, and faster, camera. By 1882, he had perfected the photographic gun he had dreamt of four years earlier. This gun was a portable camera with a single circular revolving plate on which consecutive exposures were recorded at precise intervals of time and distance. The resulting images did not produce a series of photographs of the kind Muybridge was now famous for, but were represented as twelve overlapping images on a single photograph. Muybridge had successfully achieved the decomposition of motion in his photographs, but Marey was 
now perfecting the decomposition of motion into even thinner slices of time. His new venture into what he termed chronophotography was to earn him a generous grant from the French Ministry of War. The money from the Ministry (as well as a constant supply of volunteer infantry soldiers) enabled Marey to set up a new laboratory, the Station Physiologique, in Paris. The Station was designed: 'to determine the series of actions which are created in human locomotion in its various types, to measure the effort expended at each moment in the different actions of locomotion, in order to seek the most favourable conditions for utilisation of that effort' (Marey, 1902: 34).

But Marey had a problem. Whilst Muybridge continued his instantaneous photography in pursuit of artistic expression by increasing the number of cameras and through the filming of naked and semi-naked human models, Marey felt that his own photographs contained too much information. With the shutter speed set too slow the images were too blurred to measure; if set too fast the photograph contained far too many overlapping images. In 1883, he explained: 'in this method of photographic analysis the two elements of movement, time and space, cannot both be estimated in a perfect manner. Knowledge of the positions the body occupies in space presumes that complete and distinct images are possessed; yet to have such images a relatively long temporal interval must be had between two successive photographs. But if the notion of time one desires to bring to perfection, the only way of doing so is to greatly augment the frequency of images, and this forces each of them to be reduced to lines' (cited in Douard, 1995:188). Striving for the simplicity and precision of his graphical method combined with the speed and accuracy of chronophotography, Marey found the solution in what he called geometric chronophotography (see figure three):

A man dressed completely in black, and consequently invisible upon the dead-black background, wears bright points and lines, strips of silver lace attached to his clothes along the axes of his limbs. When the man, so rigged, passes in front of the apparatus, photographs will result that will be accurate diagrams to scale, showing without confusion the posture of upper and lower arms, thighs and lower legs, and feet at each instant, as well as the oscillations of the head and the hips (Marey, 1902: 323)

\section{FIGURE THREE ABOUT HERE}


Through geometric chronophotography, Marey was able to decompose time into its 'elements'. He created an empirical geometry to reveal how continuous motion is built up out of a discontinuous series of movements. For Marey, 'chronophotography renders visible the normally invisible phases of motion or positions in space the body occupies. The data furnished by chronophotography represent the real phases of movement, which persistence of vision represents as continuous duration: the fast shutter speeds decompose movement that the eye cannot' (Douard, 1995: 195-6). Marey had finally discovered a way to visualise, capture, and measure Helmholtz's lost physiological time. Now all he had to do was to reduce it.

Armed with this new graphical language, geometric chronophotographic researchers at the Station Physiologique were able to establish 'objective' rules governing the manoeuvres of soldiers, and the physical exercises of young peoples: in short, to reveal the most efficient use of the muscular energy and effort of the human body. Marey was also mindful of other domains where his methods could be put to use. In his book Movement (1875: 139), he opined that 'the same method could equally well be applied to the teaching of movements necessary for the execution of various skilled industries. It would show how the stroke of a skillful blacksmith differed from that of a novice. It would be the same in all manual performances and in all kinds of sport.'

Marey discovered that even the most highly motor skilled of his photographic subjects were not consciously aware of their own bodily movements. But his geometric 'chronographs' provided an immediate means for measuring and improving everyone's motor skills - you simply had to study the pictures and learn to copy the representation of movement, one 'element' at a time. Marey's chronographs contained information previously hidden from both the observer and the subject. But if lost time could be captured with his pictures, they could also be used to instruct human subjects directly without recourse to the verbal or written language Marey so distrusted as a basis for scientific knowledge. For Marey, 'inefficient' unconscious inferences themselves could be subsumed into conscious, rule-bounded behaviours through the mimetic application of chronographs. In this way, Tom Gunning (2002) argues that chronophotography worked as much to master motion as to portray it, achieving through this mastery the calculation 
of the body itself, rendering visible its unseen motions, making evident its unconscious behaviour. Marey's friend and colleague at the Collège de France, Henri Bergson, was equally dismayed at the way chronophotography reduced time to calculable space and saw Marey's work as contributing to the subordination of human experience to an objective and external measure (Bergson, 1911).

Let us now return briefly to Gladwell's 'blink'. The very notion of a thin slice of time owes much to the work of nineteenth-century physiologists such as Helmholtz and Marey. But they showed that the 'blink' is not an action or property of the human eye, for the phenomenon of visual persistence reveals that what the eye 'sees' when the eyelid is closed is merely an after-image of what was 'seen' when the eyelids were open. The 'blink' is more the property of the opening and closing shutter of Muybridge's cameras. Of course, as Alan Sakula (1988) points out, 'the photograph, as it stands alone presents merely the possibility of meaning' (p 91) and so interpreting photographs requires going outside the photographs themselves to ask where and how they were used, and how the people who used them assigned them meaning. Although the technical prowess of Marey and Muybridge heralded the birth of cinematography as we now know it (and both men had met Thomas Edison in the late 1880 s to discuss possible collaborative projects), the meaning of the thin slices of photographic time they captured was inextricably bound up with the development of social Helmholzianism.

Indeed, the chronophotographs of industrial hammerers taken by Marey's student Charles Fremont at the Station Physiologique in 1895 bear a striking resemblance to those taken twenty years later by Frank and Lillian Gilbreth for their motion studies in the US. The Gilbreths used a 'cyclograph' which comprised a series of light bulbs attached to a black suit worn over a workers body filmed in semi-darkness by a cine camera. The resulting 'micromotion' pictures were then used to train workers in the 'one best way' of working. Somewhat begrudgingly, Frank Gilbreth (1914) was to confess: "Marey is the man whom I wish had not been born. He got a cyclegraph. He set up a revolving disk with a hole in it before a camera, and he photographed this, and got a chrono-cyclegraph. We had to design a clock in order to photograph time in order to get a clock that would not jump. Marey's scheme was impractical, but he did the job, and he did it first." 
Perhaps only within a discourse of social Helmholtzianism does the 'blink' become a domain of managerial practice, and one which can provoke Dagognet to see a key role for Marey's ideas in the rapid proliferation of assembly lines and Taylorist exploitations in the twentieth century. 'It could be that he was also pushing toward robotisation. It was less a man-machine or even a human machine that Marey wanted than a machine capable of replacing man; who was considered a machine of low productivity. It was enough to record and calculate the results of this machine to replace it with something better' (Dagognet, 1992: 170). It is undeniable that Marey favoured the use of inscription technologies in his search for greater bodily efficiency. 'When the eye cease to see, the ear to hear, and the sense of touch or feel, or when our senses deceive us', he wrote, 'these instruments are like a new sense of an astonishing precision' (1878a: 108). Of course, crucial to the successful deployment of geometric chronophonographical instruments was the denial of the importance of both bodily experience and the body itself. Marey's two dimensional geometric chronographs showed only 'what was strictly necessary' - by which he meant only those elements which could be presented on a graph. Yet, through the medium of photography, Marey managed to persuade a wide audience that motion naturally had the structure of a graph. This was possible because, as many researchers have noted, photography carried considerable evidentiary power in the late nineteenth and early twentieth centuries (e.g. Sontag, 1978; Stange, 1989; Banta and Hinsley, 1986; Barthes, 1981).

Photography achieved compelling stature through its ability to preserve a specific moment in time, an ability made even more believable by the contemporary iconic status of mechanical progress. Photographs, it was then argued (and is still often argued), recorded reality, and looking at a photograph told a viewer what things were really like at the moment of its production. Studying them offered evidence of the natural order of things not visible to the unassisted eye (Lindstrom, 2000: 734).

In Marey's case, the analysis and reproduction of the nervous system require the introduction of time as a function into the categories of representation. Most importantly, Braun (1994) argues, when inscription apparatuses begin to penetrate the time of the nervous system, the body loses its thickness and contours. In order to remove the 'imprint of flesh and skin so as to reveal the moving parts of the animate machine -- the joints, 
levers, and fulcrums, the rods, and pistons of the human body -- he Marey concocted a moving skeleton, denuding the body of its flesh and volume' (Braun, ibid: 81). In Braun's view, the study of the body in motion had become the study of the decomposition of moving corpses. Such studies, premised on the notion that the body will never be 'efficient' until it becomes consciously aware of its limitations, continue to the present day in ergonomic and human factors engineering laboratories throughout the world.

\section{Psychophysics and the Regimentation of the Mind}

But if the body is in need of correction, what of the unconscious mind? What of unconscious inference, the second element of Helmholtz's lost time? Muybridge and Marey had little interest in mental processes and effectively evacuated the mind from the human 'motor'. However, psychologists were keenly interested in the relationship between mind and body, and the introduction of Helmholtz's first law of thermodynamics into psychology by Gustav Fechner in 1860 heralded the birth of psychophysics as a discipline combining psychological and physiological research on the human body with physics. Psychophysics concerned itself with uncovering the physiological and psychological rules that govern mental activity and sensory perception. In short, Fechner and colleagues were searching for the physiological mechanism uniting the unconscious body and the conscious mind. Fechner was aided on this search by Helmholtz and his doctoral student, Wilhelm Wundt, who shared a fascination with the concept of unconscious inference. In their experiments on animals, Helmholtz and Wundt were able to thin-slice lost physiological time to 30 milliseconds, but did this instant of time have any psychological significance? The men were convinced that 'the will, the senses, the associations and apperception all rigorously follow the principles of energy conservation' (Wundt, 1914: 900). Moreover, Fechner showed that mental events could not only be measured, but measured in terms of their relationship to real, physical events.

Fechner's psychophysical research on, and deep interest in, the unconscious may well have passed quietly into obscurity were it not for the profound influence it had on a young neurology student attending his lectures at Leipzig University during the 1873-4 academic year. The student's name was Sigismund Schlomo Freud (a name he changed to Sigmund Freud four years later). Freud was later to apply Helmholtz's first law of 
thermodynamics to psychological phenomenon as he was convinced that it was emotional rather than muscular energy that held the key to understanding human behaviour. Like Charles Darwin, Freud perceived emotion as a form of physical energy which obeyed physical laws, and like Wundt, he regarded conscious ideas as representations of physical forces.

In 1885, Freud moved to Paris to study with the neurologist Jean-Martin Charcot. Freud was immensely impressed by Charcot's work on traumatic hysteria and from it he developed the idea that one of the principal forms of neurosis came about when a traumatic experience led to the formation of unconscious symptoms. Freud based his theory of psychodynamics on the recognition that memories repressed in the unconscious create increasing tension, and that this was relieved with dischargelike phenomena when the unconscious was made conscious. Hence, 'psychic energy' can neither be created nor destroyed, but can only be converted from one form to another. He suggested that negative energy or anxiety from our childhood conflicts could not be destroyed, just as the first law of thermodynamics would have it, but is pushed, or repressed, out of conscious awareness. The unconscious (or id) functions to contain such repressed wishes, and a (conscious) ego serves to guide and direct the expenditure of energy. Our instincts, contained in the id, simply represent internal energy the ego must somehow channel and relieve to restore 'psychic constancy' or 'neuronic inertia'.

In his 1895 Project for a Scientific Psychology, Freud argued that the neuronal system held the key to understanding human behaviour and cognition. Neurons build up energy which must be discharged when it goes beyond a tolerable level; pain is the eruption of too much energy, whilst pleasure is the release of energy. Freud believed that we all strive to keep energy at a minimum and thus our ultimate goal is achieving pleasure and avoiding pain. When wishes that could lead to pain emerge, however, our unconscious defence mechanisms repress them. This unreleased energy is then often displaced through substitute wishes or it seeps out into our dreams. Failure to release this energy could lead to the development of neuroses and mental instability.

So, for Freud, the unconscious was far more than some kind of momentary mediator of perception which serves to reduce the efficiencies of the body. It was a crucial component in all our behaviour, full of wishes, desires and needs having a 
biological and intra-psychological origin, which obey established physical laws. But it could not be measured on a graph or photographed. Freud's psychotherapeutic techniques were developed to reveal this unreleased energy and facilitate its release into conscious awareness through lengthy consultation with a qualified psychiatrist.

\section{The Engineering of Consent and the Management of the Unconscious}

Freud's work, of course, is most commonly associated with mental illness and the 'talking cure', and, for the best part of half a century, psychologists stayed well clear of his ideas when studying 'normal' behaviour. Indeed, it wasn't until the late 1950s that the term 'unconscious' appeared in mainstream US psychology texts (Greenwald, 1992), and even then it was primarily the focus of fierce criticism from empirical psychologists who could not 'see' or measure it. But Freud had propelled the notion of the unconscious into popular consciousness and, in the US in the 1920s, two strands of applied psychodynamic psychology emerged which were to revolutionise the way the thin slice of the unconscious inference came to be understood and applied to business management practices. These two strands became known as human relations and public relations.

Human Relations. Towards the end of the 1920s, the famous Hawthorne experiments began at the Western Electric Company in Chicago. Although early research in the company focused on psycho-physiological and ergonomic aspects of work (e.g. the effect of changes in illumination on productivity), once the Australian psychologist Elton Mayo became involved, the studies soon changed tack to concentrate on channeling the unconscious, emotional energy of manual workers towards higher productivity (Bruce, 2006). With explicit reference to Freud (and implicit reference to Helmholtz's first law of thermodynamics), Mayo (1923a) believed that everyone has unconscious thoughts ('unacknowledged reveries') which, if acknowledged, lead to self-awareness, social maturity, and good citizenship. But, when these are not consciously acknowledged, they become 'negative reveries' which can fester into obsession, irrationality, and neurosis (Mayo, 1923b). The solution to such melancholia was counselling, and Mayo instigated an eight-year counselling and interviewing programme with 10,000 workers during the later stages of the Hawthorne studies. The object of this programme was to 'acknowledge' the reveries of the workers by allowing them to express their frustrations 
to a sympathetic counsellor, thereby reducing inner tension and at the same time mitigating the forces of industrial unrest (Roethlisberger \& Dickson, 1939).

Public Relations. Freud did not believe that the unconscious is restricted to 'primitive processing', or that 'higher order' thought is restricted to the conscious mind. For example, in The Interpretation of Dreams he observed, 'the most complicated achievements of thought are possible without the assistance of consciousness' (1976: 751). Freud's nephew Edward Bernays worked tirelessly to promote the application of this idea to the practical business of social persuasion and propaganda in the United States. In his hugely influential Crystallizing Public Opinion, Bernays (1923) argued that Freud's concept of the unconscious could, and should, be utilised by social elites to 'so mold the mind of the masses that they will throw their newly gained strength in the desired direction' (p. 20). Governments and business corporations, he insisted, should 'regiment the mind like the military regiments the body' (p. 21). Here Bernays is promoting the idea of regimenting the mind in precisely the same way as Marey and the Gilbreths were seeking to regiment the body. The secret was to by-pass conscious awareness and appeal directly to those unconscious needs and desires his uncle had uncovered in his research.

Both Mayo and Bernays regarded the unconscious thought processes of the individual as an obstacle to the betterment of democratic society. Edward Bernays' 'regimentation of the mind' is accomplished by what he termed the engineering of consent. This is achieved through taking advantage of the unconscious mind's tendency to self-deception and of falling prey to the seductive power of a strong leader. Mayo held a similar view, although he was more worried that industrial unrest was primarily caused by the seductive power that strong trade union leaders held over workers suffering from negative revery (Gillespie, 1991). If all managers developed counselling skills to dissipate this unconscious energy, Mayo insisted, conscious reason would be restored, union leaders would lose their power, and industrial unrest would be confined to the dustbin of history.

For many years, knowledge of the work of Mayo and Bernays was restricted to a fairly select band of academics and politicians. But, in the US, public awareness of the role of the unconscious in decision-making and behaviour was aroused by the publication 
in 1957 of Vance Packard's book, The Hidden Persuaders. In this best-selling book, Packard described many of the new motivational research marketing techniques (many of them pioneered by Bernays) being employed to sell products to the American consumer. That same year, a market researcher called James Vicary coined the term 'subliminal advertising' to describe how consumer behaviour could be shaped by images flashed up on a cinema or television screen so quickly that they fell far below the viewer's threshold of conscious awareness. Vicary conducted an experiment at a drive-in cinema in Fort Lee, New Jersey to prove his point. He placed a tachistoscope in the cinema's projection booth, and throughout the playing of the film Picnic, he flashed a couple of different messages on the screen every five seconds. The messages were each displayed for only $1 / 300$ th of a second at a time. The result of displaying the imperceptible suggestions -'Drink Coca-Cola' and 'Hungry? Eat Popcorn' - was an 18\% increase in Coca-Cola sales, and a $58 \%$ surge in the sale of popcorn to the audience. Whilst Marey had analysed the gaps in between his photographic images in order to bring to conscious awareness the lost time the eye could not see, Vicary placed a message in these gaps which the eye could see, but the conscious mind could not.

The public outcry fuelled by Packard's book and Vicary's experiment was such that the US Federal Communications Commission came under intense pressure to ban subliminal advertising from radio and television. A ban was finally instigated on January $24^{\text {th }}, 1974$ following an announcement by the FCC that subliminal techniques, 'whether effective or not,' were 'contrary to the public interest,' and that any broadcasting station employing them risked losing their licence to broadcast. Although Vicary admitted in 1960 that he had falsified his research results in order to publicise his marketing business, the idea that corporations or governments might be controlling the unconscious minds of consumers and citizens resonated strongly with the Cold War paranoia of the time.

Within academia, the consequent rise of what Pratkanis (1992) has called the 'cargo-cult science of subliminal persuasion' served to put Helmholtz's 'lost time' firmly back on the experimental research agenda. Then, in 1979, the neuroscientist Benjamin Libet announced the results of his experimental study of unconscious inferences. His results rocked the scientific and philosophical academies to the core. Libet based his study on the psychophysiological work of Kornhuber and Deeke (1965). Kornhuber and 
Deeke asked volunteers to move their right index finger and then measured this voluntary movement with a strain gauge whilst simultaneously recording the electrical activity of the brain by means of an electrode on the skull. They discovered that each movement was preceded by a brief upsurge of electrical activity in the brain. They called this the 'readiness potential' and found that it occurred approximately one second before the voluntary movement. Libet followed up this study with an experiment in which he asked volunteers to lift a finger whenever they felt the urge to do so. He placed an electrode on a volunteer's skull and confirmed a readiness potential about one second before the person lifted his or her finger. He then compared the time it took for the person to will the movement with the time of the readiness potential. To his amazement, Libet found that the readiness potential appeared not after, but 200 milliseconds before his subjects felt the urge to move their finger. Thus, by observing the electrical activity of the brain on a graphical device (an electroencephalograph, or EEG), Libet was able to predict what his subjects would do before they were consciously aware of having decided to act.

Now, whilst many commentators have questioned the conclusions Libet drew from this and subsequent experiments (specifically regarding the status of free will), they are in general agreement that 'voluntary acts are nonconsciously initiated' (Gomes, 1998: 591). More specifically, there is approximately a half-second delay between a bodily action and becoming consciously aware of that action, between setting an act in motion and our decision to do so. What an opportunity, perhaps, for mnemotechnical management through insinuating a product or instruction in this tiny gap between the unconscious and conscious awareness. After all, as Nietzsche (1990: 112) has argued, 'a mere disciplining of thoughts and feelings is virtually nothing, one first has to convince the body. In two or three generations everything is already internalised. It is decisive for the future of nations and of mankind that one should inaugurate culture in the right place - not in the soul. The right place is the body, demeanour, diet, physiology: the rest follows'.

\section{Conclusion: Towards a Neuro-Scientific Management?}

From the mid- $19^{\text {th }}$ century on, new forms of calculation in sensory registers developed which were not previously regarded as 'political'. This paper has outlined three technical 
developments which were fundamental to the growth of what Thrift (2004) terms 'micro biopolitics'. First, the development of graphical devices and instruments enabled the small spaces of the body to become visible and measurable. Second, the development of chronophotography enabled the smallest and fastest of bodily movements to be seen, recorded, and manipulated. Third, the development of the technical means to manage knowledge of unconscious actions (e.g. via time and motion study, counselling, and advertising) has enabled the reterritorialisation of behavioural control away from the labouring body to the dictates of mindful management. All three of these developments need to be seen in the context of a discourse of the labouring body epitomised by 'social Helmholzianism' which renders the embodied unconscious amenable to correction.

More than 100 years after the meeting in Paris between Helmholtz, Marey, and Muybridge, after the birth of psychophysics, and after Freud's initial conceptualisation of the unconscious; mainstream cognitive psychology has finally woken up to the fact, longaccepted and exploited by business and political elites (and behavioural psychologists), that the embodied unconscious plays a key role in shaping human behaviour. Just as Marey's chronophotography reduced the body to a basic motor and skeletal line drawing, the deeper workings of our unconscious sensorium are now being reduced to graphical and photographic images by cognitive scientists armed with ever sophisticated technologies of representation and measurement.

There is now growing evidence that businesses are eager to exploit more fully the unconscious influences of the senses of sound (Corbett, 2003a, 2003b) and smell (Bone and Ellen, 1999; Corbett, 2006), as well as the sensorium more generally (Howes, 2004; Lindstrom, 2005 ) on employee and consumer behaviour. This raises the spectre of new forms of organisational practices based on a nascent 'neuro-scientific management', aimed at the exploitation of the micro biopolitics of work behaviour. Yet, whilst the influence of Taylorism of management thinking and organisational behaviour has been endlessly debated in management and organisation studies, the role of applied physiologists, whose work reflected and reinforced an ideology of 'social Helmholzianism', has received rather less attention. 


\section{References}

Ambady, N. and Rosenthal, R. (1993) 'Half a minute: predicting teacher evaluations from thin slices of nonverbal behavior and physical attractiveness'. Journal of Personality and Social Psychology, 64, 431-441.

Banta, M. and Hinsley, C. M. (1986) From Site to Sight: Anthropology, Photography and the Power of Imagery. Cambridge, Mass:

Barthes, R. (1981) Camera Lucida: Reflections on Photography. New York: Hill and Wang.

Bergson, H. (1911) Creative Evolution. New York: Greenwood Press.

Bernays, E. (1923) Crystallizing Public Opinion. New York: Kessinger.

Braun, M. (1994) Picturing Time: The Work of Etienne-Jules Marey (1830-1904)

Chicago: University of Chicago Press.

Bruce, K. (2006) 'Henry S. Dennison, Elton Mayo, and Human Relations histiography'. Management and Organizational History, 1, 177-199.

Corbett J.M. (2003a) 'Sound organisation: a brief history of psychosonic management'. Ephemera: critical dialogues on organization, 3, 261-272.

Corbett, J.M. (2003b) 'I sing the body (in)corporate: identity, displacement and the radical priority of reception'. In Critique and Inclusivity: Critical Management Studies 3 edited by M. Brigham, C. Brown and Associates. Lancaster: AMS Press.

Corbett, J.M. (2006) 'Scents of identity: organisation studies \& the cultural conundrum of the nose'. Culture and Organisation, 12, 221-232.

Dagognet, F. (1992) Etiennes-Jules Marey: A Passion for the Trace. New York: Zone Books. 
Douard, J. W. (1995) 'E.-J. Marey's visual rhetoric and the graphic decomposition of the body.' Studies in the History of the Philosophy of Science, 26, 175-204.

Freud, S. (1976) The Interpretation of Dreams. London: Pelican Books.

Gilbreth, F.B. (1914) 'Typescript: 5 October'. Gilbreth Collection: N file, Container 59, Folder NAPTMC/0324-2A. Purdue University Library.

Gillespie, R. (1991). Manufacturing Knowledge: A History of the Hawthorne Experiments. Cambridge: Cambridge University Press.

Gladwell, M. (2006) Blink: The Power of Thinking Without Thinking. Harmondsworth: Penguin.

Greenwald, A.G. (1992) 'New Look 3: unconscious cognition reclaimed'. American Psychologist, 47, 766-779.

Gomes, G. (1998) 'The timing of conscious experience: a critical review and reinterpretation of Libet's research'. Consciousness and Cognition, 7, 559-595

Gunning, T. (2002) 'Early cinema and the avant garde'. Paper presented at the Workshop on Early Cinema and the Avant-Garde, Vienna, March $8^{\text {th }}-13^{\text {th }}$.

Haas, R. B. (1976) Muybridge: Man in Motion. Berkeley: University of California Press.

Helmholtz, H. (1850/1948) 'On the rate of transmission of the nerve impulse'. In Readings in the History of Psychology edited by W. Dennis. New York: AppletonCentury-Croft.

Helmholtz, H. (1873) Popular Lectures on Scientific Subjects. London: Longmans Green.

Howes, D. (1991) 'Hyperesthesia, or, the sensual logic of late capitalism'. In Empire of the Senses edited by D. Howes. Oxford: Berg. 
Jahanshahi, M. and Hallett, M. (eds) (2003) The Bereitschaftspotential MovementRelated Cortical Potentials. New York: Plenum Publishers.

Kornhuber, H.H. and Deeke, L. (1965) 'Cerebral potential changes in voluntary and passive movements in man: readiness potential and reafferent'. Archiv für die Gesamte Physiologie, 284, 1-17.

Libet, B. (1979) 'Subjective referral of the timing for a conscious sensory experience'. Brain, 102, 193-224.

Lindstrom, M. (2005) Brand Sense: Build Powerful Brands through Touch, Taste, Smell, Sight and Sound. New York: Simon and Schuster.

Lindstrom, R. (2000) 'They all believe they are undiscovered Mary Pickfords: workers, photography, and scientific management'. Technology and Culture, 41, 725-751.

Marey, E.J. (1872) Le Machine Animale, Locomotion Terrestre et Aérienne. Paris: Masson.

Marey, E.J. (1878a) La Methode Graphique dans les Sciences Experimentales et Principlement en Physiologies et Medecine. Paris: Masson.

Marey, J.E. (1878b) 'Letter to the editor'. La Nature, December $9^{\text {th }}$, page 29.

Marey, E.J. (1902) ‘The history of chronophotography'. Smithsonian Institute Annual Report 1901. Washington, DC: Smithsonian Institute Publications.

Marey, E, J. (1895) Movement. London: Heinemann Press

Mayo, E. (1923a) 'The irrational factor in human behavior'. Annals of the American Academy of Political and Social Science, 110, 117-130.

Mayo, E. (1923b) 'Irrationality and revery'. Journal of Personnel Research, 1, 477-483. 
Muybridge, E. (1879) 'Instantaneous photographs of animals in motion'. La Nature, March $22^{\text {nd }}$, p. 246.

Muybridge, E. (1881) The Attitudes of Animals in Motion: A Series of Photographs Illustrating the Consecutive Positions Assumed by Animals in Performing Various Movements. New York: Dover Publications.

Nietzsche, F. (1990) Twilight of the Idols. Harmondsworth: Penguin.

Pratkanis, A. R. (1992) 'The cargo-cult of subliminal persuasion'. Skeptical Inquirer, 16, 260-272.

Rabinbach, A. (1990) The Human Motor: Energy, Fatigue, and the Origins of Modernity. New York: Basic Books.

Roethlisberger, F. J., \& Dickson, W. J. (1939) Management and the Worker. Cambridge, MA: Harvard University Press.

Sekula, A. (1988) 'On the invention of photographic meaning'. In Thinking Photography edited by V. Burgin.. London: Sage.

Sontag, S. (1978) On Photography. New York: Picador.

Stange, M. (1989) Symbols of Ideal Life: Social Documentary Photography in America, 1890-1950. Cambridge: Cambridge University Press.

Thrift, N. (2004) 'Intensities of feeling: towards a spatial politics of affect'. Geographiska Annales, 86, 55-76.

Wundt, W. (1914) Grundiss der Psychologhie. Leipzig: Periodicals Service Company. 


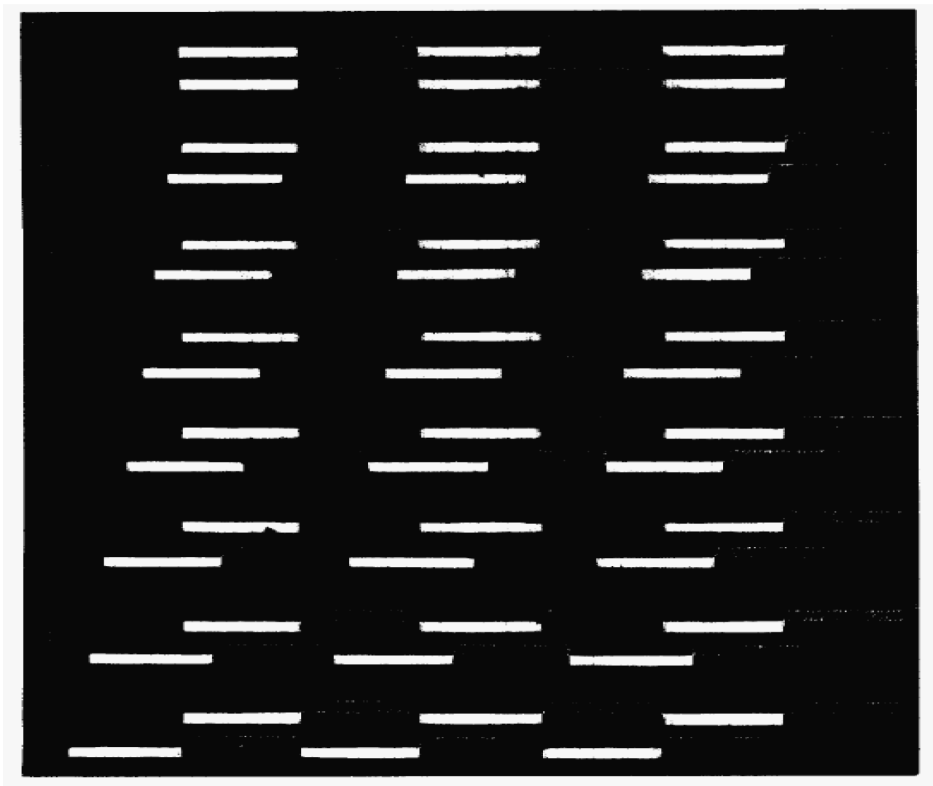

FIGURE ONE: Marey's notation representing a horse's gait (1872) 


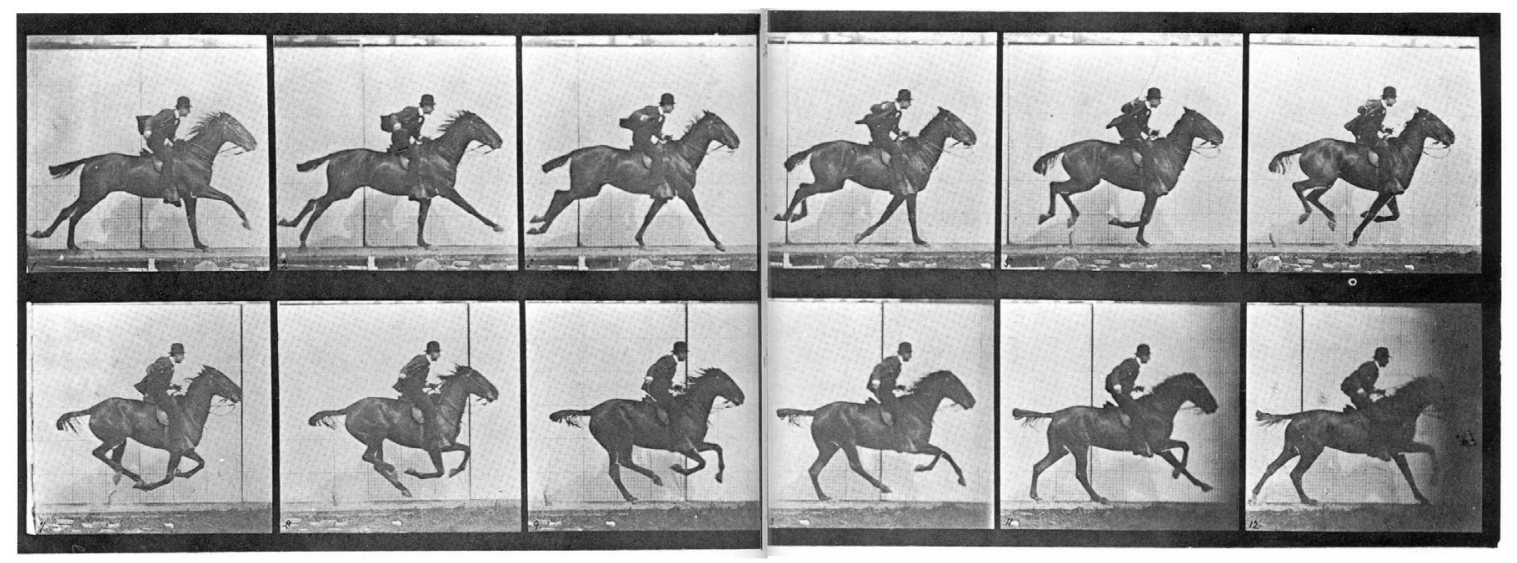

Figure Two: Muybridge's instantaneous photographs of Occident (1877) 


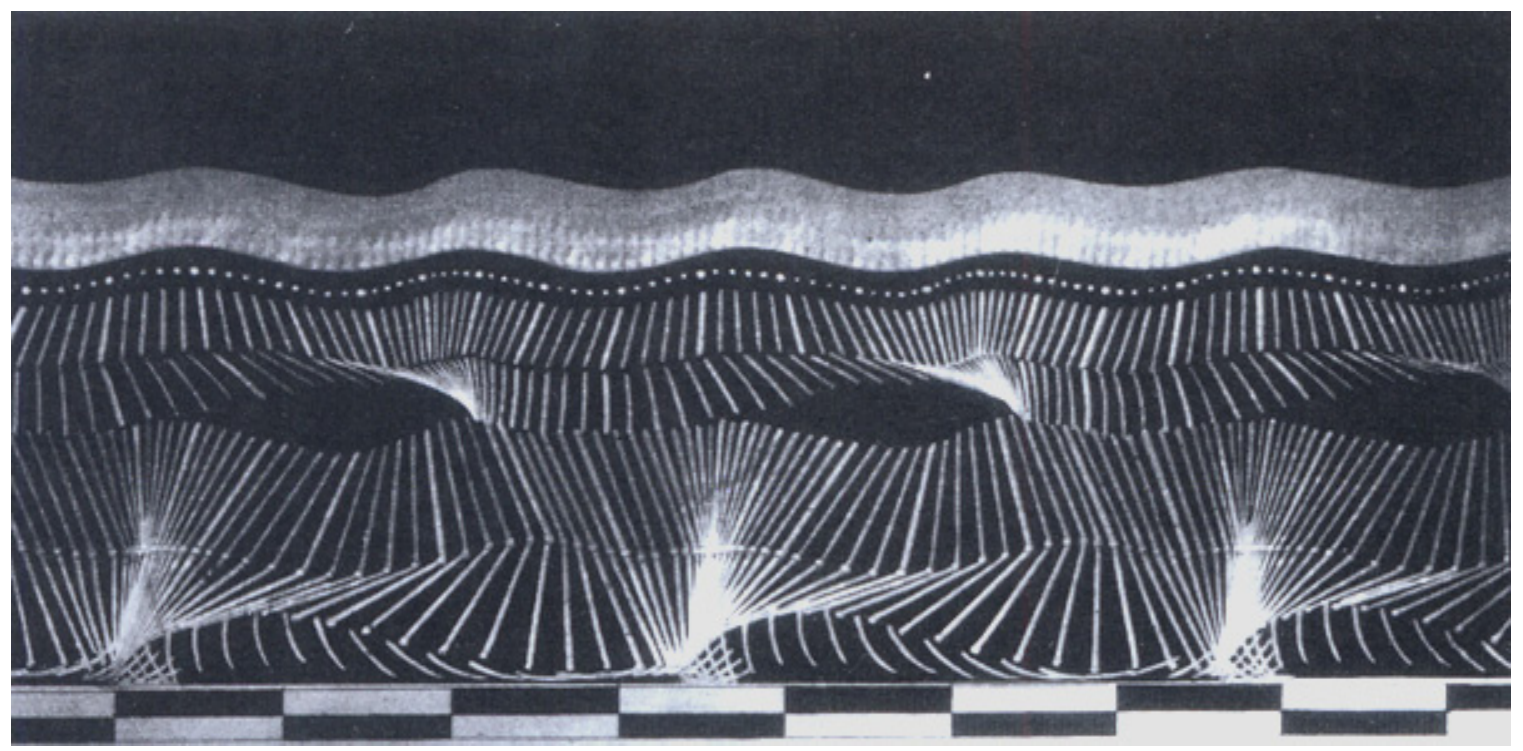

Figure Three: Marey's geometric chronophotograph of a man running 